\title{
Modelling of Hysteresis in Vibration Control Systems by means of the Bouc-Wen Model
}

\author{
Chia-Ming Chang, ${ }^{1}$ Salvatore Strano, ${ }^{2}$ and Mario Terzo ${ }^{2}$ \\ ${ }^{1}$ Department of Civil Engineering, National Taiwan University, Taipei, Taiwan \\ ${ }^{2}$ Department of Industrial Engineering, University of Naples Federico II, Naples, Italy \\ Correspondence should be addressed to Mario Terzo; m.terzo@unina.it
}

Received 24 July 2015; Revised 19 October 2015; Accepted 25 October 2015

Academic Editor: Chao Tao

Copyright (c) 2016 Chia-Ming Chang et al. This is an open access article distributed under the Creative Commons Attribution License, which permits unrestricted use, distribution, and reproduction in any medium, provided the original work is properly cited.

The review presents developments concerning the modelling of vibration control systems with hysteresis. In particular, the review focuses on applications of the Bouc-Wen model that describes accurate hysteretic behaviour in vibration control devices. The review consists of theoretical aspects of the Bouc-Wen model, identification procedures, and applications in vibration control.

\section{Introduction}

Vibration control systems are adopted for the suppression or, at least, the attenuation of undesirable vibrations that can affect systems and structures, such as buildings, vehicles, aircraft, and bridges. These systems often show nonlinear behaviour due to variable material properties, changeable geometry, and additional nonlinear devices, resulting in hysteresis phenomena. To predict system responses, many hysteretic models have been developed.

Hysteresis is a nonlinear behaviour encountered in a wide variety of processes in which the relation between input and output variables involves memory effects. The detailed physical modelling of these systems is an arduous task, and the models obtained are often too complex to be used in realworld applications [1]. For this reason, alternative models of systems with hysteresis have been proposed. These models combine some physical understanding of the hysteretic system with some black-box modelling, named "semiphysical" models.

Over the years, various semiphysical models of hysteresis have been proposed. One of the most widely adopted ones is the Bouc-Wen hysteresis model $[2,3]$. The best feature of this model is its versatility; that is, through appropriate choices of model parameters, it can represent a wide variety of softening or hardening smoothly varying or nearly bilinear hysteretic behaviours.
The Bouc-Wen model has been extensively used in the current literature to mathematically describe components and devices with hysteretic behaviours. Thus, the objective of this literature review is to provide engineers and researchers with an overview of the work that addresses the modelling of vibration control systems by means of the Bouc-Wen model. This review is divided into three major parts: Section 2 focuses on the mathematical and physical properties of the Bouc-Wen model, whereas Section 3 focuses on identification of the Bouc-Wen model parameters. Section 4 provides results concerning several vibration control case studies in which the effectiveness of the Bouc-Wen model, for the accurate description of hysteresis, is verified.

\section{Mathematical Properties of the Bouc-Wen Model}

In this section, a description of the mathematical formulation of the Bouc-Wen model is presented.

Consider, as an example, the equation of motion of a single-degree-of-freedom (SDOF) mechanical system:

$$
m \ddot{u}(t)+c \dot{u}(t)+F(t)=f(t),
$$

where $m$ is the mass, $u(t)$ is the displacement, $c$ is the linear viscous coefficient, $F(t)$ is the restoring force, and $f(t)$ is the 

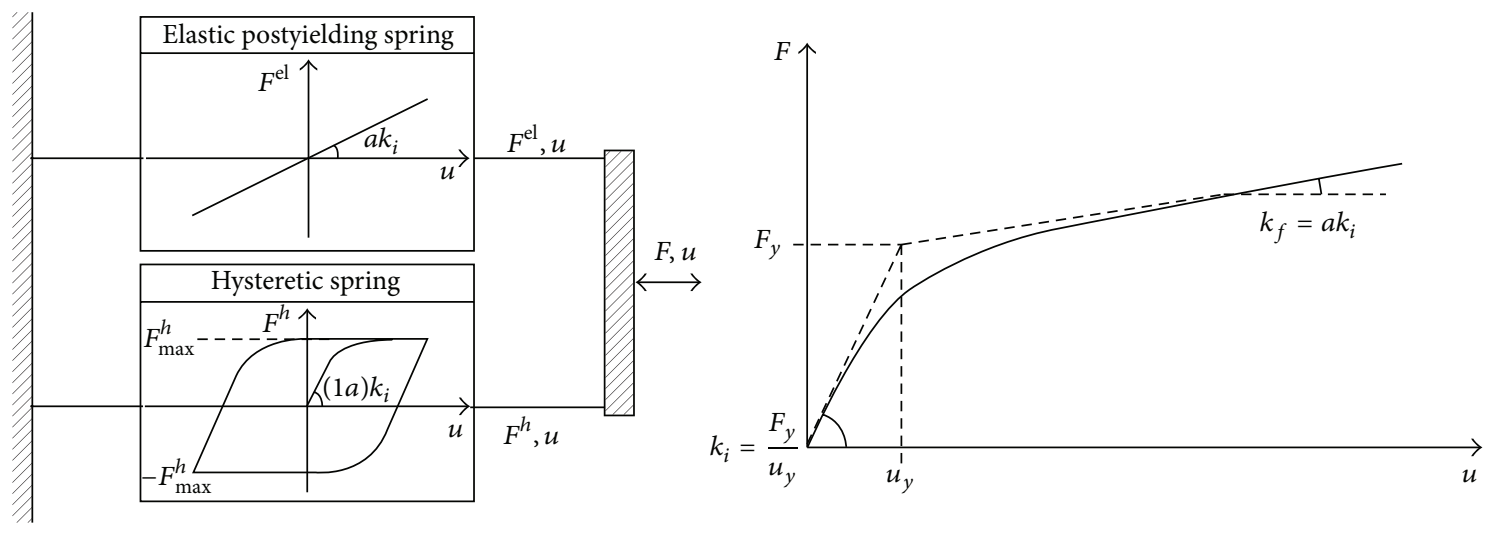

Figure 1: Bouc-Wen model [4].

excitation force; the overdot indicates derivative with respect to time. is

The restoring force $F(t)$, based on the Bouc-Wen model,

$$
F(t)=a \frac{F_{y}}{u_{y}} u(t)+(1-a) F_{y} z(t)
$$

where $a:=k_{f} / k_{i}$ is the ratio of postyield stiffness $k_{f}$ to preyield stiffness $k_{i}:=F_{y} / u_{y}, F_{y}$ is the yield force, $u_{y}$ is the yield displacement, and $z(t)$ is a nonobservable dimensionless hysteretic variable that obeys the following nonlinear differential equation with zero initial condition $(z(0)=0)$ :

$$
\dot{z}(t)=\dot{u}(t)\left\{A-[\gamma+\beta \operatorname{sgn}(\dot{u}(t) z(t))]|z(t)|^{n}\right\} .
$$

The coefficients $A, \beta, \gamma$, and $n$ are dimensionless quantities that control the behaviour of the model and $\operatorname{sgn}(\cdot)$ is the signum function. For small values of the positive exponential parameter $n$ the transition from elastic to postelastic branch is smooth, whereas for large values the transition becomes abrupt, approaching that of a bilinear model. The parameters $\beta$ and $\gamma$ control the size and shape of the hysteretic loop. The notation varies from paper to paper and very often the places of $\beta$ and $\gamma$ are exchanged.

From (2) it follows that the restoring force $F(t)$ can be divided into an elastic and a hysteretic part as follows:

$$
\begin{aligned}
& F^{\mathrm{el}}(t)=a \frac{F_{y}}{u_{y}} u(t)=a k_{i} u(t)=k_{f} u(t), \\
& F^{h}(t)=(1-a) k_{i} z(t) .
\end{aligned}
$$

Thus, the model can be visualized as two springs connected in parallel [4] (Figure 1).
The parameters of the Bouc-Wen model have the following criteria:

$$
\begin{aligned}
& a \in[0,1], \\
& k_{i}>0, \\
& k_{f}>0, \\
& c>0, \\
& A>0, \\
& n>1, \\
& \beta>0, \\
& \gamma \in[-\beta, \beta] .
\end{aligned}
$$

In [23], it has been proved that the parameters of the BoucWen model are functionally redundant, and indeed multiple parameter vectors can produce an identical response under a given excitation. This redundancy can be then removed by fixing parameter $A$ to unity [23].

Constantinou and Adnane [24] suggested the constraint $A /(\beta+\gamma)=1$ in order to reduce the total number of unknown parameters to six: $\gamma, n, a, F_{y}, u_{y}$, and $c$.

In [25], an asymmetrical Bouc-Wen model has been obtained adjusting the velocity as

$$
\dot{u}(t) \longleftarrow(\dot{u}(t)-\operatorname{sgn}(u(t))),
$$

where $\mu$ is the scale factor for the adjustment.

Modification of the Bouc-Wen model presented in [2628] included strength, stiffness, and pinching degradation effects, by means of suitable degradation functions:

$$
\begin{aligned}
\dot{z}(t) & =\frac{h(z(t))}{\eta(\varepsilon)} \dot{u}(t)\{A(\varepsilon) \\
& \left.-v(\varepsilon)\left[\beta \operatorname{sgn}(\dot{u}(t))|z(t)|^{n-1} z(t)+\gamma|z(t)|^{n}\right]\right\},
\end{aligned}
$$

where $\varepsilon$ is the absorbed hysteretic energy and the functions $\nu(\varepsilon), \eta(\varepsilon)$, and $h(z)$ are associated with strength, stiffness, and 
pinching degradation effects, respectively. $\nu(\varepsilon), A(\varepsilon)$, and $\eta(\varepsilon)$ are linearly increasing functions defined as

$$
\begin{aligned}
\nu(\varepsilon) & =v_{0}+\delta_{\gamma} \varepsilon(t), \\
A(\varepsilon) & =A_{0}-\delta_{A} \varepsilon(t), \\
\eta(\varepsilon) & =\eta_{0}+\delta_{\eta} \varepsilon(t) .
\end{aligned}
$$

The pinching function $h(z)$ is

$$
h(z)=1-\varsigma_{1}(\varepsilon) \exp \left(-\frac{\left(z(t) \operatorname{sgn}(\dot{u})-q z_{u}\right)^{2}}{\left(\varsigma_{2}(\varepsilon)\right)^{2}}\right),
$$

where

$$
\begin{aligned}
& \varsigma_{1}(\varepsilon)=(1-\exp (-p \varepsilon(t))) \varsigma, \\
& \varsigma_{2}(\varepsilon)=\left(\psi_{0}+\delta_{\psi} \varepsilon(t)\right)\left(\lambda+\varsigma_{1}(\varepsilon)\right),
\end{aligned}
$$

and $z_{u}$ is the ultimate value of $z$, given by

$$
z_{u}=\sqrt[n]{\frac{1}{v(\beta+\gamma)}} .
$$

The additional model parameters are $\delta_{v}>0, \delta_{A}>0, \delta_{\eta}>$ $0, v_{0}, A_{0}, \eta_{0}, \psi_{0}, \delta_{\psi}, \lambda, p$, and $\varsigma$. When $\delta_{v}=0, \delta_{\eta}=$ 0 , or $h(z)=1$, respectively, no strength degradation, stiffness degradation, or pinching effect is considered in the model.

It is important to note that a Bouc-Wen model could present a good match with the real data for a specific input, while it could not necessarily keep significant physical properties for different exciting inputs. On the basis of this consideration, the physical and mathematical properties of the Bouc-Wen model are comprehensively discussed in [1] and it has been found that if the system parameters respect the constraints

$$
\begin{aligned}
n & \geq 1, \\
u_{y} & >0, \\
A & >0, \\
\beta+\gamma & >0, \\
\beta-\gamma & \geq 0,
\end{aligned}
$$

then the model is valid independently of the exciting input. When (12) are satisfied, (3) can be expressed in a normalized form.

Defining the parameters

$$
\begin{gathered}
\rho=\frac{A}{u_{y} z_{0}}>0, \\
\sigma=\frac{\beta}{\beta+\gamma} \geq \frac{1}{2}, \\
z_{0}=\sqrt[n]{\frac{A}{\beta+\gamma}},
\end{gathered}
$$

it follows

$$
\begin{aligned}
& \dot{w}(t) \\
& \quad=\rho \dot{u}(t)\left\{1+|w(t)|^{n} \sigma\left[1-\operatorname{sgn}(\dot{u}(t) w(t))-\frac{1}{\sigma}\right]\right\}
\end{aligned}
$$

with

$$
w(t)=\frac{z(t)}{z_{0}} .
$$

In [29], it is demonstrated that $w(t)$ is bounded in the range $[-1,1]$.

Substituting (14) and (15) in (2), it follows

$$
F(t)=k_{f} u(t)+k_{w} w(t),
$$

where

$$
k_{w}=(1-a) F_{y} z_{0}>0 .
$$

Consequently, the unknown parameters of the normalized form of the Bouc-Wen model are $\rho, \sigma, n, k_{f}$, and $k_{w}$ with the following constraints:

$$
\begin{aligned}
\rho & >0, \\
\sigma & \geq \frac{1}{2}, \\
n & \geq 1, \\
k_{f} & >0, \\
k_{w} & >0 .
\end{aligned}
$$

The model parameters can be determined by system identification techniques, using experimental input and output data.

\section{Bouc-Wen Model Parameter Identification}

The identification of the Bouc-Wen model parameters is performed by adopting an identification algorithm that compares model output signals and those measured, for the same input signals, in order to determine the unknown model parameters. Nonlinearity of the Bouc-Wen model introduces the complexity for parameter identification. Several methods, based on different approaches, have been then proposed. In this section, an overview of different identification algorithms is presented.

An iterative least-squares procedure, based on a modified Gauss-Newton approach, was presented in [5]. Identification was carried out to estimate the parameters of an extended Bouc-Wen model that accounts for strength and stiffness degradation in accordance with [26]. The system identification procedure is shown in Figure 2.

In [30], a vibration control system composed of a magnetorheological damper in series with a magnetorheological elastomer was presented. The Bouc-Wen model was adopted to reproduce the hysteresis of the magnetorheological damper, and the parameters were identified using a leastsquares method. 


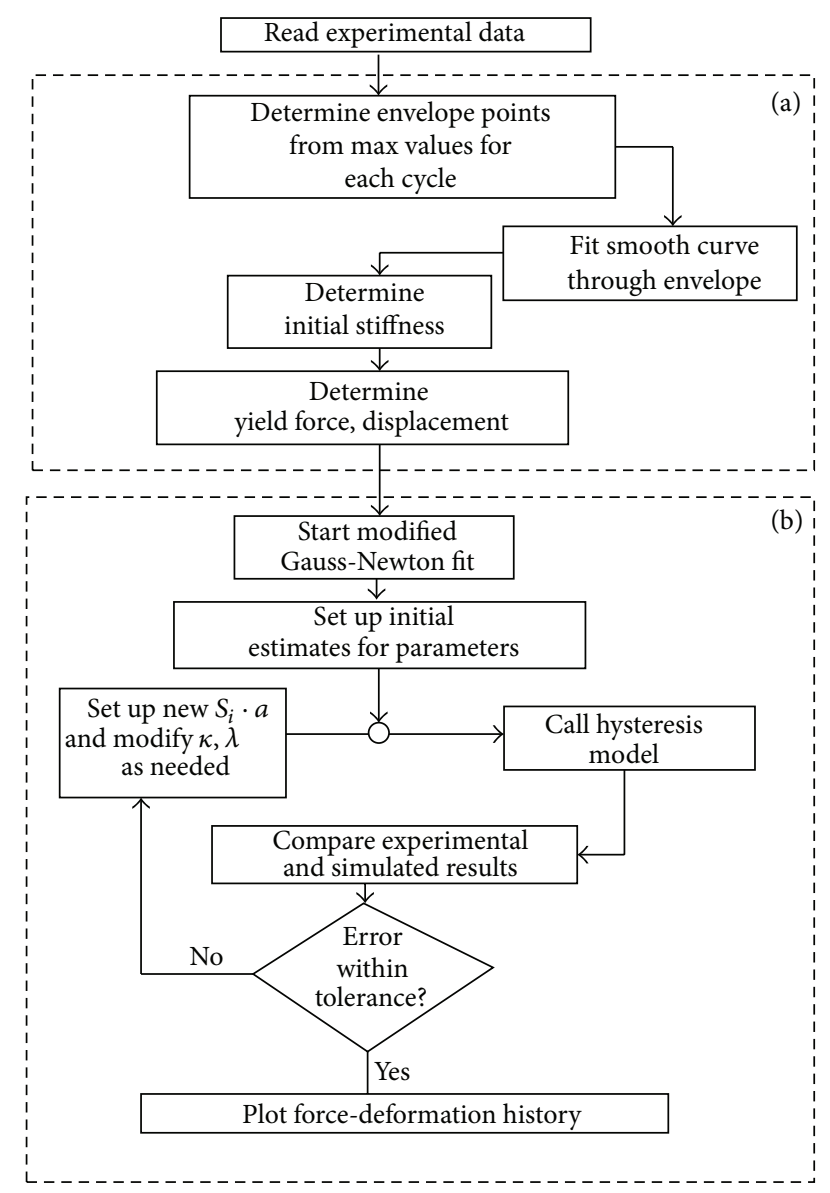

FIgURE 2: Flow diagram for complete identification process [5].

On-line parameter identification of the Bouc-Wen model has also drawn a lot of attention to researchers. Studies in $[31,32]$ presented an on-line identification method using a least-squares adaptive law. Another study in [33] employed an adaptive on-line identification methodology with a variable trace method to adjust the adaptation gain matrix. In [34], a linear parameterized estimator was established for the on-line estimation of the hysteretic Bouc-Wen model with unknown coefficients (including the parameter $n$ ). In [35], an adaptive on-line identification algorithm was proposed for parametric and nonparametric identification of structural models and was applied to a generalized Bouc-Wen model. The proposed identification methodology was a recursive least-squares algorithm that required only acceleration measurements.

In addition to the least-squares regression method, a genetic based identification algorithm was proposed in [36]. The reproduction procedure adopts the roulette wheel selection and the method of crossover and uniform mutation [37].

To account for asymmetric behaviour, a modified BoucWen model [6] was adopted for modelling a PZT actuator. A modified particle swarm optimization algorithm [38] was proposed in order to identify and optimize the model parameters (see Figure 3). The fitness function in Figure 3 is evaluated as the root-mean-square error between the actual measured displacement and the model output.

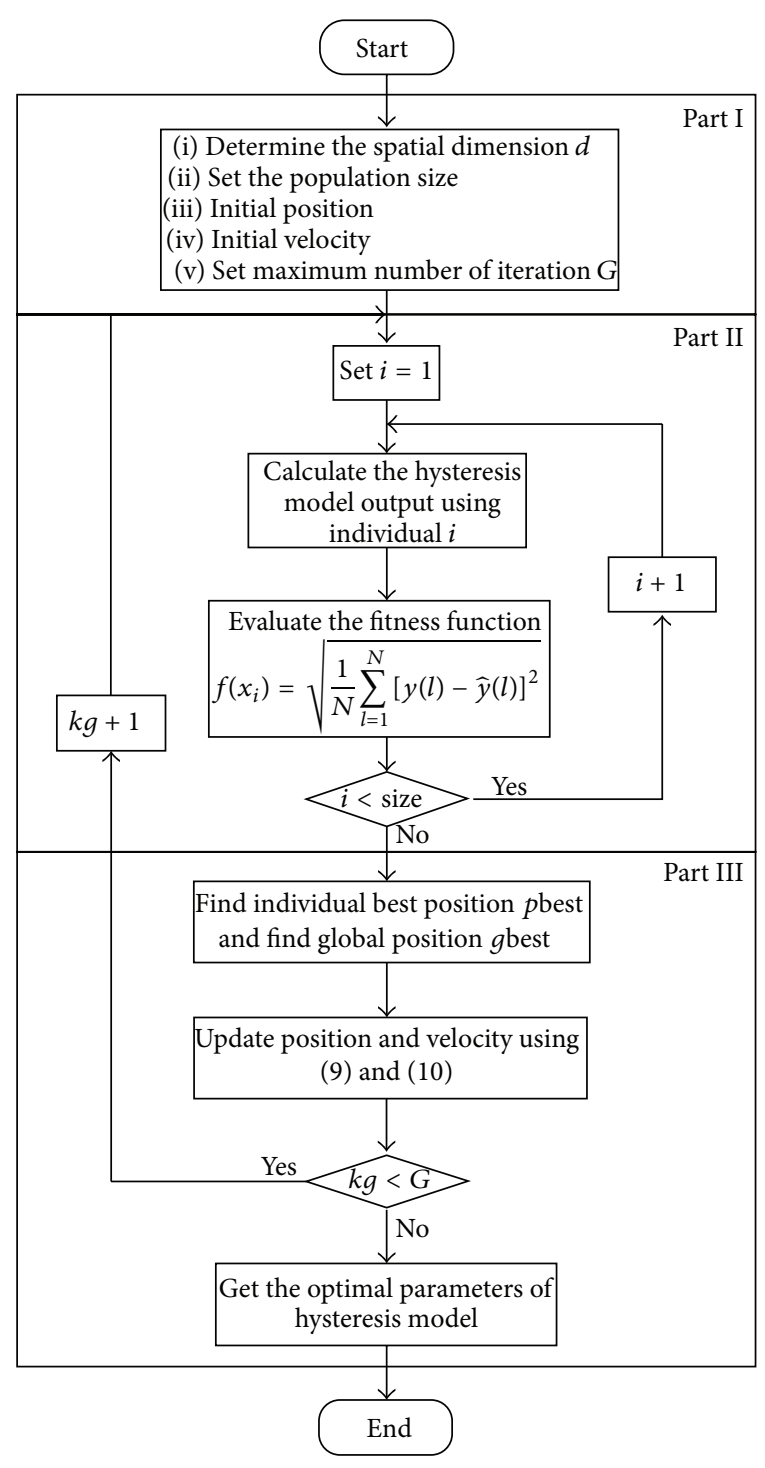

FIGURE 3: Flowchart of the identification hysteretic model parameters [6].

The particle swarm optimization was also adopted in [39] to identify the parameters of Bouc-Wen model. In this study, the identified model was used to describe the dynamics of a large-scale magnetorheological damper for seismic hazard mitigation.

Gauss-Newton iterations were used as a method of estimating the parameters of hysteretic system with slip on the basis of input-output data [40]. Reference [41] proposed a frequency domain parametric identification method of nonlinear hysteretic isolators. In [42, 43], an identification method for the normalized Bouc-Wen model was developed. Using the analytical description of the hysteresis loop developed in [29], an algorithm was proposed along with its analytical proof. It consisted in exciting the Bouc-Wen model with two periodic signals with a loading-unloading shape (wave periodic) which gives rise asymptotically to a hysteretic periodic response. The obtained two limit cycles 


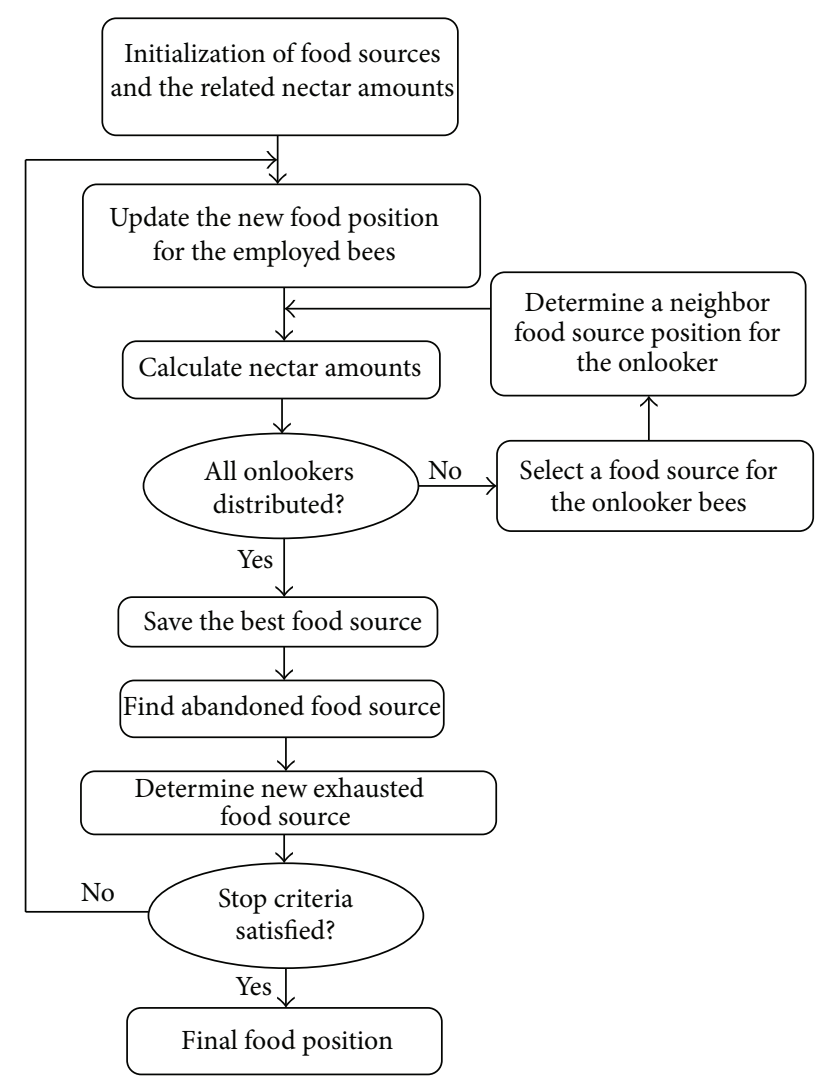

FIGURE 4: Flowchart of the parameter identification algorithm presented in [7].

were then used as an input to exactly determine the unknown parameters.

The limit cycle approach was also adopted in [10] to identify the parameters of the Bouc-Wen model adopted to reproduce the hysteresis of a wire-cable vibration isolator. In [44], the limit cycle approach was adopted to identify the parameters of a large-scale magnetorheological fluid damper model.

Another optimization method based on artificial bee colony algorithm [7, 45] was developed to determine the optimum parameters of Bouc-Wen hysteretic systems. The proposed flowchart is shown in Figure 4.

In $[46,47]$, a constrained nonlinear optimization was exploited in parametric identification. In [48], the BoucWen nonlinear hysteresis term was approximated by a power series expansion of suitable basis functions, and then the coefficients of the functions were determined using the standard least-squares method.

Bouc-Wen model parameters could be also identified with procedures based on nonlinear filtering, using, for example, the extended Kalman filter (EKF) or the unscented Kalman filter (UKF). Yang and Ma [49] proposed a constrained EKF with a global weighted iteration strategy, which was effective in estimating all the parameters of the BoucWen model of hysteresis. Zhang et al. [50] also applied the EKF for the identification of hysteretic systems that exhibit degradation and pinching; all the parameters of the BWmodel were identified without problem.

In [51-53], the UKF was used for the identification of nondegrading and degrading hysteretic systems. The identification results show that the UKF is well suited for the identification of complicated nonlinear systems and that this methodology can yield accurate estimates of the parameters of the Bouc-Wen models. The results also show that the UKF outperforms the EKF with regard to computational efficiency and robustness to measurement noise levels.

\section{Vibration Control System Modelling Using the Bouc-Wen Model}

The main scope of the vibration control is the suppression or, at least, the attenuation of undesirable vibrations that can affect systems and structures, such as buildings, vehicles, aircraft, and bridges. Vibration control is typically realized using passive, semiactive, or active [54-58] systems, and considerable hysteretic behaviours can be found in each of these.

Passive vibration control, such as the passive base isolation, is one solution that has proven effective for enhancing structural performance against seismic events. The main concept behind passive base isolation is to increase the structure flexibility, thus avoiding potentially dangerous seismic ground motions [59-62]. Base isolation bearings have been installed in many buildings for seismic protection [63]; however, large base displacements resulting from the increased flexibility of the passive isolation system can potentially exceed the prescribed limit of structural designs under severe seismic excitations [64-66].

Semiactive vibration control consists of a passive isolation system combined with a controllable semiactive device [6771]. Semiactive vibration control is one control technique that consumes less power to change the features of the isolation system, but no mechanical energy is introduced into the structural system. Differently from passive control techniques, semiactive control systems have higher variability due to the different capabilities of energy dissipation from the control devices when the power levels are changed, such as variable stiffness and/or damping values.

Active vibration control is another control technique which uses the energy generated from the active control devices, supplied by means of an external power source, to improve the vibrational system performance. The mitigation of the vibration phenomena is based on the employment of suitable actuators that transmit mechanical energy to the structure and, in recent years, a great number of studies have been accomplished on active vibration control of flexible structures using piezoelectric actuators. Among the several kinds of actuation systems, piezoelectric ceramic materials have received much diffusion in the active vibration control because of their mechanical simplicity, small volume, light weight, large useful bandwidth, efficient conversion between electrical energy and mechanical energy, and easy integration with various metallic and composite structures [72]. 


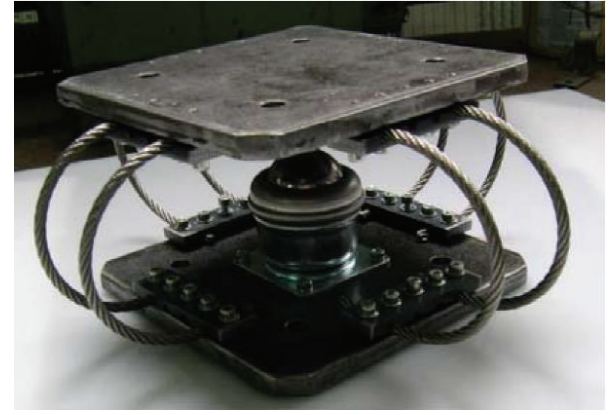

FIGURE 5: Isolator prototype [8].

4.1. Passive Systems. The Bouc-Wen model has been widely adopted for the numerical modelling of passive hysteretic control devices. In this section, an overview of various components for different applications is presented.

Passive seismic isolators aim to reduce the earthquake input energy to the structure to keep linear structural vibration. Many devices are strongly nonlinear, showing different hysteretic behaviours. In this context, the Bouc-Wen model has been used extensively for its intrinsic ability in describing the behaviour of a wide range of real-world passive seismic isolators.

In [8], a prototype seismic isolator, composed of a wire rope spring and a ball transfer unit, was proposed as shown in Figure 5. The nonlinear behaviour of the restoring force was represented by the Bouc-Wen model.

The Bouc-Wen model was used in [73] to model the dissipated energy by the wire rope isolators for seismic protection of equipment in buildings. In $[9,10]$, modified Bouc-Wen models were adopted to numerically reproduce hardening behaviours [9] (see Figure 6) or asymmetrical hysteresis cycles [10] (see Figure 7) of wire rope isolators.

A combined energy dissipation system was presented in [11]. As shown in Figure 8, a lead rubber damper (LRD) and its parallel connection with an oil damper (OD) were used in the braces of a structural frame. The restoring force characteristic of the LRD was then simulated by the BoucWen hysteretic model.

In [12], the Bouc-Wen model was employed to mathematically represent two different elastomeric seismic isolators (see Figure 9), characterized by different characteristics because of the elastomeric layers and reinforcements (in the following indicated with "IUT_a" and "IUT_b," resp.). The experimental and simulated hysteresis cycles for IUT_a and IUT_b were demonstrated in Figures 10(a) and 10(b), respectively.

In [74], the Bouc-Wen model was utilized to mathematically model a frictional behaviour of Teflon sliding bearings for a base isolation application. The study in [13] facilitated the Bouc-Wen model to describe the behaviour of hysteretic dampers that interconnect two adjacent structures subjected to seismic excitation as shown in Figure 11.

Effectiveness of dissipative passive devices used as connections between two structures was investigated [75]. An analytical model for the response of a reinforced concrete

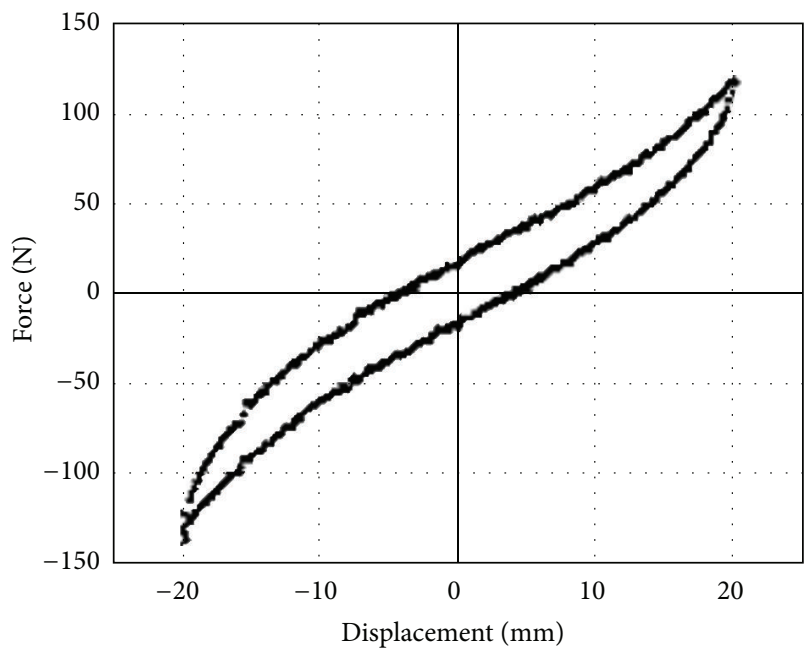

Figure 6: Hysteresis cycle with hardening [9].

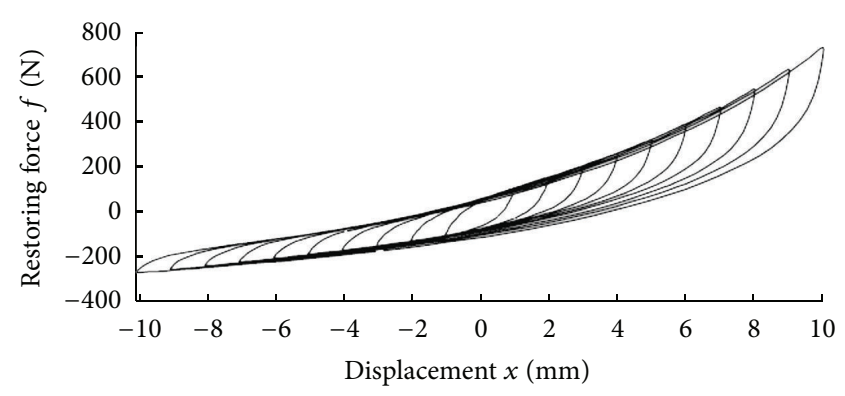

FIgURE 7: Asymmetrical cycles for tension-compression loading of a wire rope isolator [10].

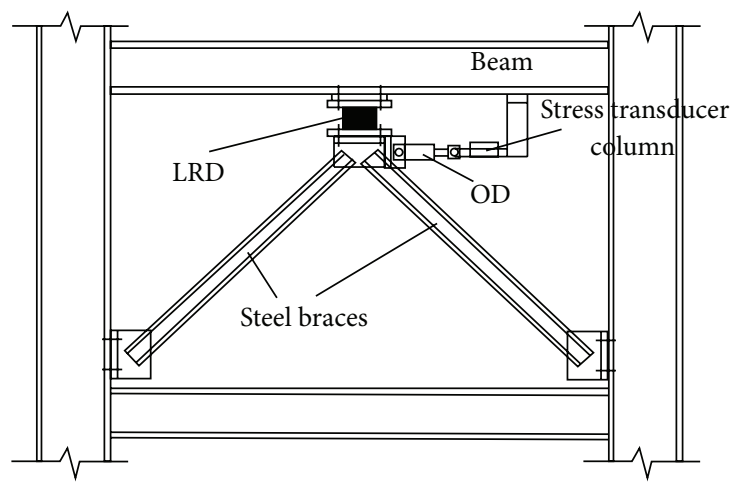

FIGURE 8: The configuration of the combined energy dissipation system in a frame [11].

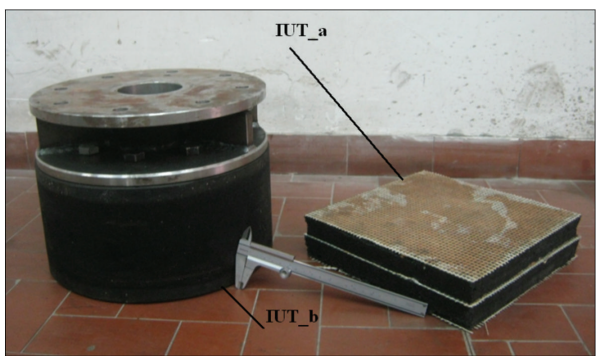

FIGURE 9: Seismic isolators presented in [12]. 


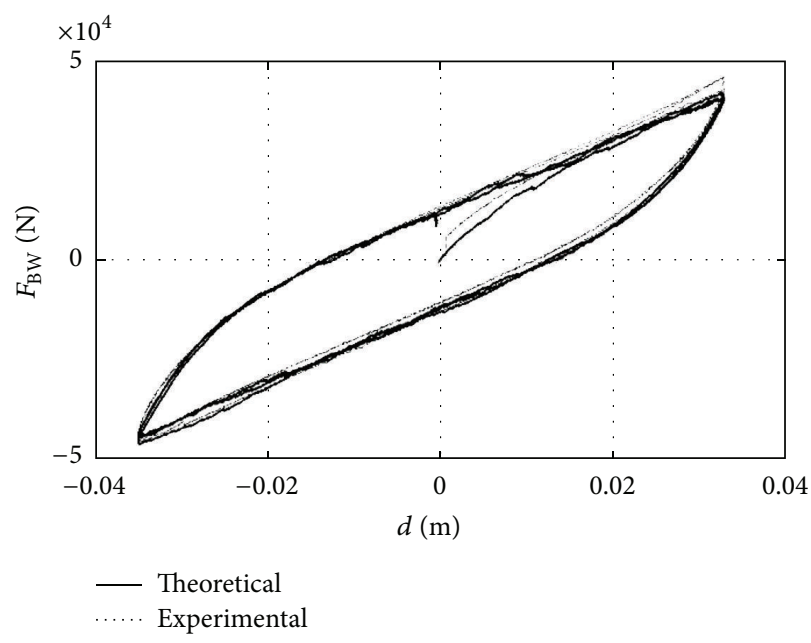

(a)

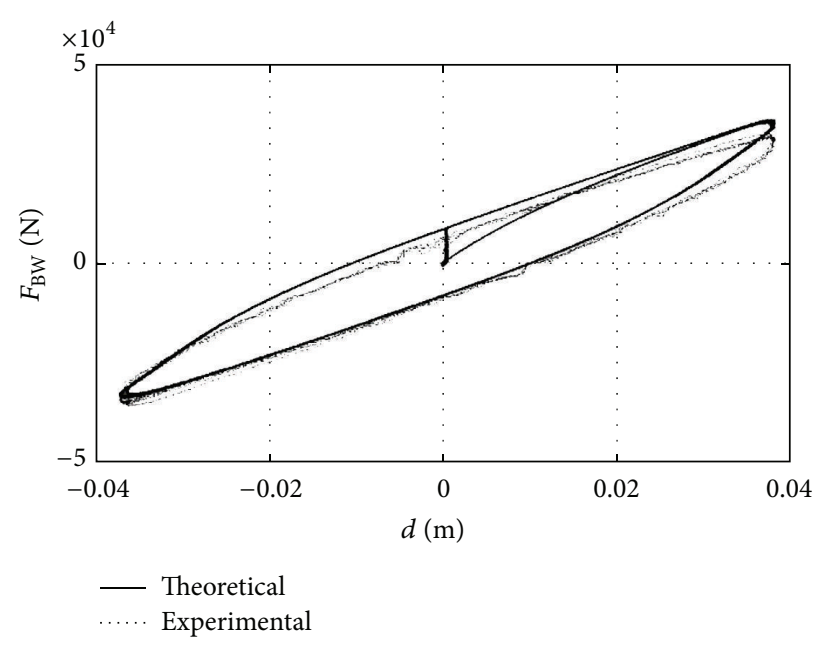

(b)

FIGURE 10: Experimental and simulated hysteretic cycles: (a) IUT_a; (b) IUT_b [12].

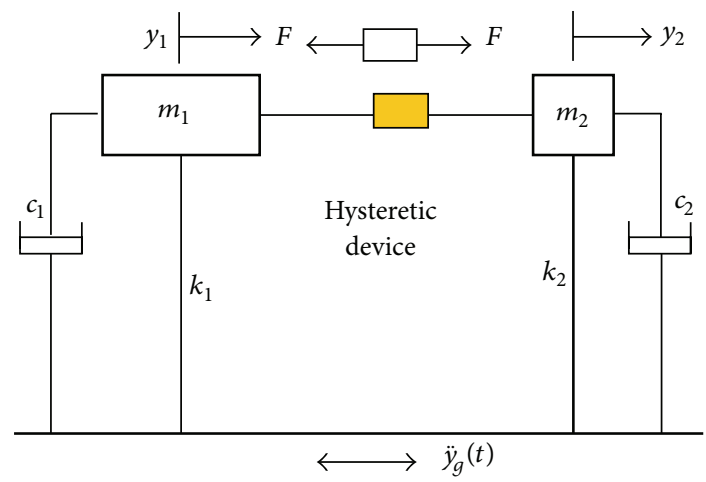

FIGURE 11: Schematic of the hysteretic device that interconnects two adjacent structures [13].

panel with friction energy dampers was presented. The modelling of the hysteretic device was developed using an extended Bouc-Wen model. In [14], the study verified that the Bouc-Wen model well predicted the responses of suspension seats of the off-road machines to transient inputs as shown in Figure 12. The Bouc-Wen model used in [14] is shown schematically in Figure 13. The Bouc-Wen coefficients were obtained by minimizing the difference between the predicted and measured acceleration of a load supported in the seat. The measured hysteresis force-deflection cycles for the bottom buffers are shown in Figure 14. The study in [14] concluded that the Bouc-Wen model can provide a useful simulation of an existing seat.

4.2. Semiactive Systems. The magnetorheological (MR) fluids consist of suspensions of micron-sized ferrous particles immersed in a carrier fluid; their rheological behaviour can be changed by means of an applied magnetic field.

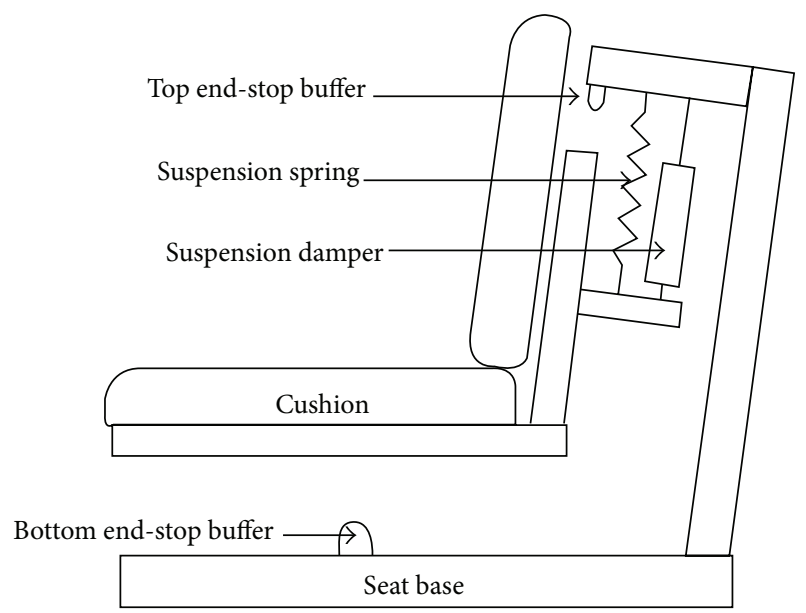

FIGURE 12: Schematic of the industrial truck seat [14].

Researchers have used the controllable variation in yield stress to develop various smart devices [76-79]. In recent years, magnetorheological dampers have been widely studied as a controllable engineering component because of their continuously controllable mechanical properties and rapid response [80]. As shown in Figure 15, MR dampers can operate under three different fluid working modes [15]: shear $[81,82]$, flow [83-85], and squeeze [86-89]. The shear mode occurs when one wall of a gap translates or rotates relative to the other wall. In the shear mode, the fluid is sheared parallel to the walls. The flow mode occurs when two walls of a gap are fixed, as in a valve system, and the fluid flows through the gap and along the longitudinal axis of the walls. The squeeze mode occurs when the walls move toward each other, squeezing out the fluid. The fluid in the squeeze mode flows orthogonally to the direction of wall motion. According to the motion of the 


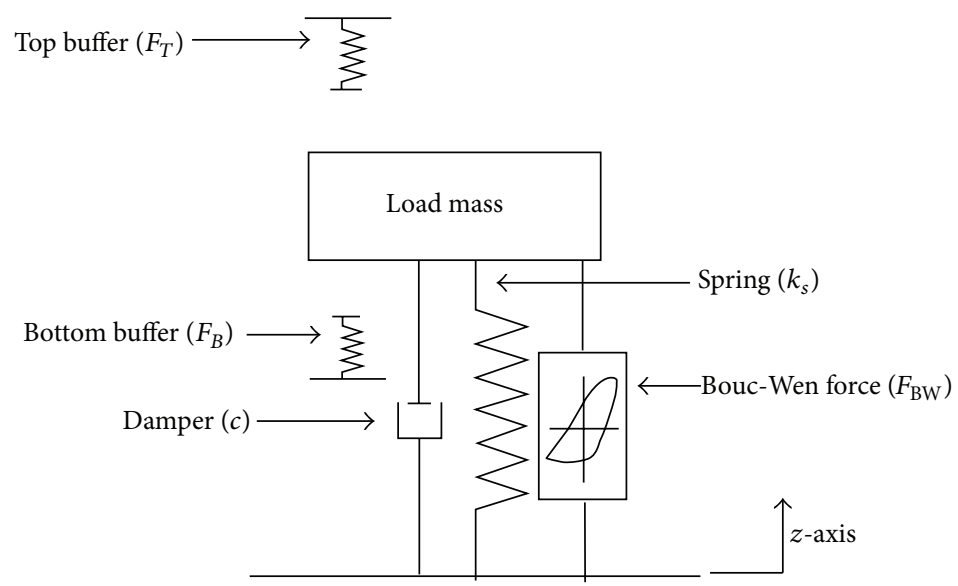

FIGURE 13: Schematic of the Bouc-Wen model [14].

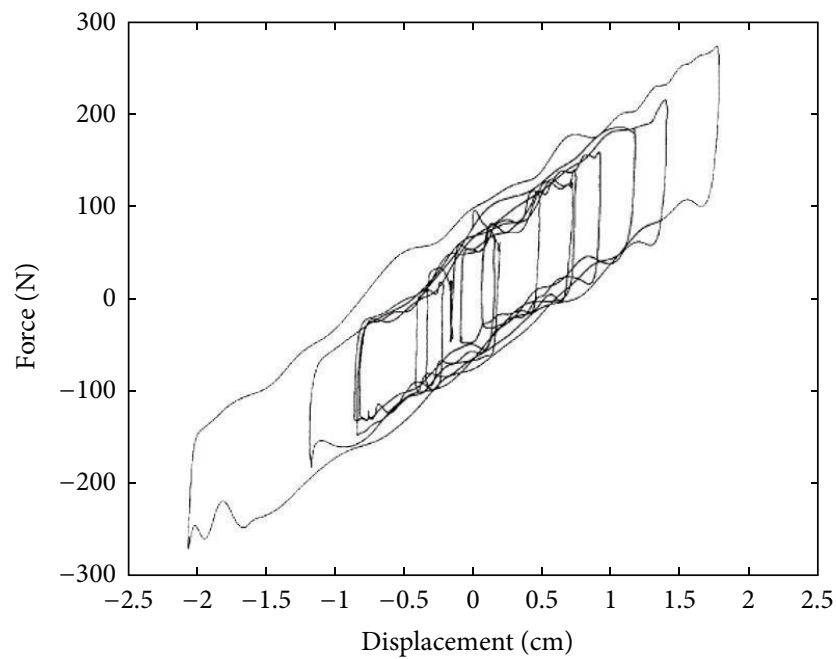

Figure 14: Force-displacement diagram-industrial truck seat exposed to random excitation [14].

constitutive elements, MR dampers can be categorized as linear MR dampers [16] (see Figure 16) and rotary MR dampers.

The modelling of MR dampers represents an important role to accurately describe their behaviours. A validated dynamic model allows executing several fundamental steps such as performance prediction, design, numerical simulations, and control synthesis. To this end, it is important to highlight the hysteretic phenomenon that occurs in these devices. Indeed, as it can be observed from experimental data in Figure 17, a hysteretic loop appears in the force-velocity diagram.

Several approaches have been established to model the MR dampers, and among these, the parametric approach drew considerable attention to researchers. The parametric models were developed using the schematization of the device as a combination of different physical elements, and a typical example was constituted by the Bouc-Wen hysteresis operator-based dynamic model [20, 90-93].

The Bouc-Wen model has been extensively applied to simulate the hysteresis loops since it possesses the force-displacement and force-velocity behaviour of the MR dampers. In the following, the most widely adopted approaches will be presented. Spencer Jr. et al. [15, 17] employed the Bouc-Wen hysteretic operator to represent the hysteretic behaviour of MR dampers, and the schematic of the proposed simple Bouc-Wen model for MR dampers is shown in Figure 18 [15, 17]. The damping force in this system is given by

$$
F=c_{0} \dot{x}+k_{0}\left(x-x_{0}\right)+\alpha z,
$$

where $c_{0}$ and $k_{0}$ are the viscous damping and stiffness, respectively; $x_{0}$ represents an initial displacement due to the presence of an accumulator; $z$ is the evolutionary variable governed by (3). By adjusting the parameter values $\alpha, \beta, \gamma$, and $n$, the force-velocity relationship is characterized.

Later, Spencer Jr. et al. [15, 17] proposed a modified BoucWen model to predict the behaviour of MR dampers over a wide range of inputs as shown in Figure 19. The model is given by the following equations:

$$
F=c_{1} \dot{y}+k_{1}\left(x-x_{0}\right),
$$

where

$$
\begin{aligned}
& \dot{y}=\frac{1}{c_{0}+c_{1}}\left[\alpha z+c_{0} \dot{x}+k_{0}(x-y)\right], \\
& \dot{z}=-\gamma|\dot{x}-\dot{y}||z|^{n-1} z-\beta(\dot{x}-\dot{y})|z|^{n}+A(\dot{x}-\dot{y}),
\end{aligned}
$$

and $k_{1}$ is the accumulator stiffness; $c_{0}$ and $c_{1}$ are the viscous damping observed at large and low velocities, respectively; $k_{0}$ is the stiffness at large velocities; $x_{0}$ is the term that accounts for the presence of an accumulator. The scale and shape of the hysteresis loop can be adjusted by $\gamma, \beta, A$, and $n$.

To model the behaviour of the shear mode MR damper (see Figure 20(a)), a Bouc-Wen hysteresis operator-based 


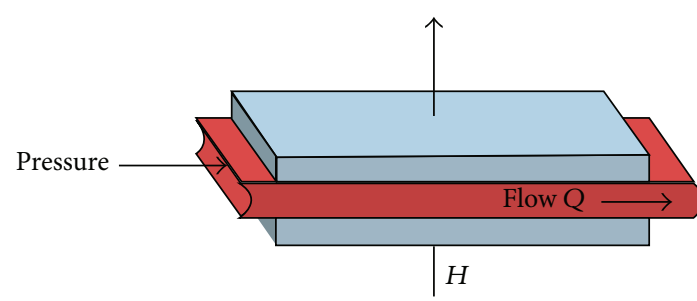

(a)

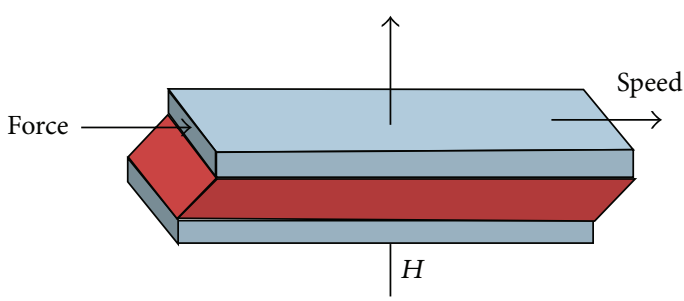

(b)

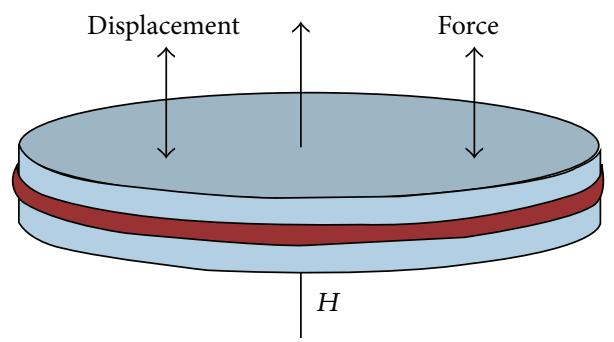

(c)

FIGURE 15: MR fluid operational modes [15]: (a) the flow mode, (b) the direct shear mode, and (c) the squeeze mode.

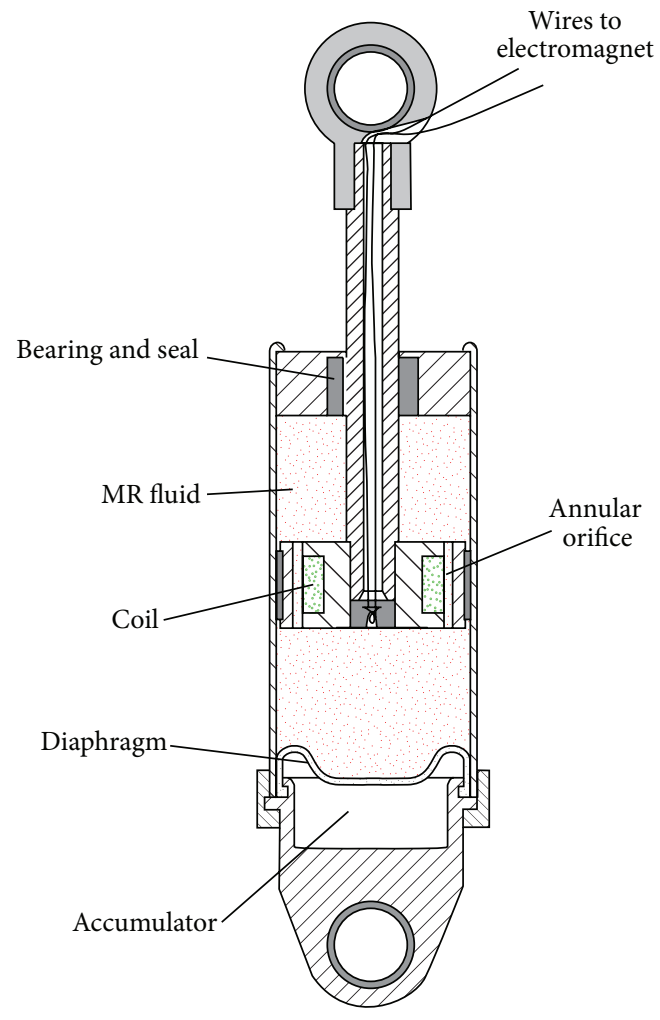

FIgURE 16: Typical scheme of a linear MR damper [16].

dynamic model, as shown in Figure 20(b), was proposed $[18,19]$. The equation governing the damping force is given by

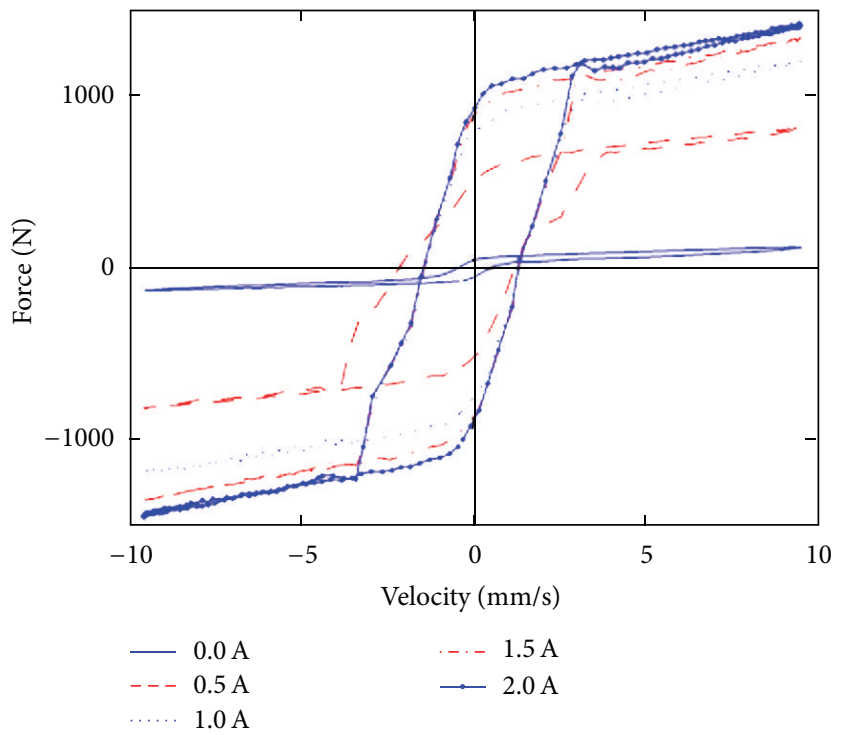

FIGURE 17: The damping force versus velocity [16].

where $z$ is the evolutionary variable given by (3). The BoucWen model in Figure 21 was developed for large-scale MR dampers [20], and the damper force is given by

$$
F=m \ddot{x}+c_{0}(\dot{x}) \dot{x}+k_{0} x+\alpha z+f_{0} .
$$

In (23), $m$ is the equivalent mass; $k_{0}$ is the accumulator stiffness; $f_{0}$ is the damper friction force; $z$ is the evolutionary variable governed by $(3) \cdot c_{0}(\dot{x})$ is given by

$$
c_{0}(\dot{x})=a_{1} e^{-\left(a_{2}|\dot{x}|\right)^{p}}
$$

where $a_{1}, a_{2}$, and $p$ are positive constants.

$$
F=c_{0} \dot{x}+\alpha z
$$




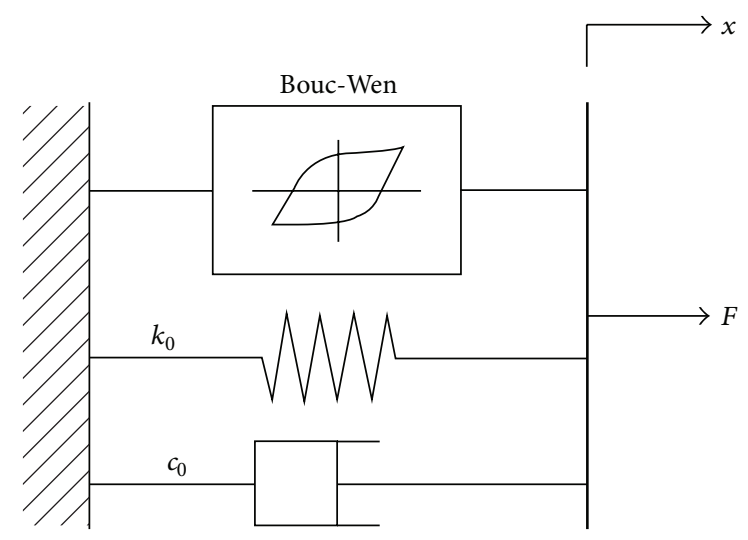

FIGURE 18: Simple Bouc-Wen model for MR dampers [15, 17].

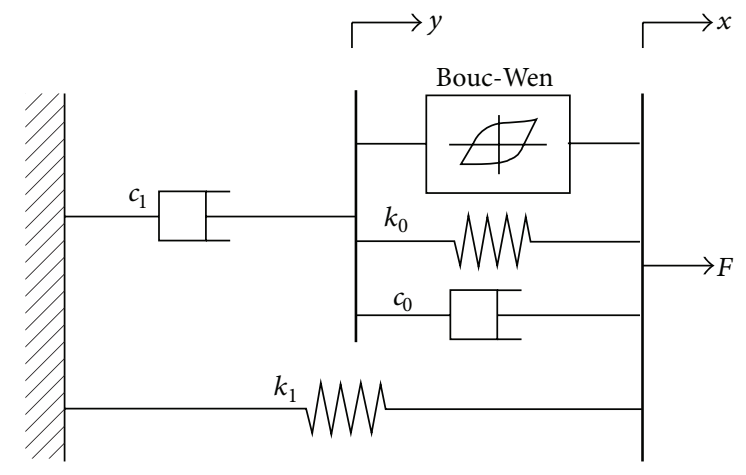

FIGURE 19: Modified Bouc-Wen model for MR dampers [15, 17].

4.3. Active Systems. Piezoelectric actuators (PEAs) represent a functional tool in the field of the active vibration control and, in the recent years, extensive researches have been conducted for modelling and control. PEAs utilize the converse piezoelectric effect of piezoelectric materials to generate displacement and force. Indeed, a piece of piezoelectric material will be mechanically strained if subject to an electric field (by placing it into the electric field or applying voltages to its surfaces).

The hysteresis nonlinearity constitutes one of the principal key issues to be solved in PEAs and its modelling is of fundamental importance for their control. In PEAs, hysteresis exists in both the electric field- (voltage-) polarization relationship and the electric field- (voltage-) strain (deformation or displacement) relationship (Figure 22), with the latter being mostly of concern in micro- and nanopositioning systems, and it is caused by the nonlinearities in the converse piezoelectric effect of the unit cells and the switching and movement of domain walls $[21,94]$.

The hysteresis trajectory of a PEA can be treated as being composed of three types of components: (1) the major loop which is the hysteresis loop that spans the whole input (voltage) range, (2) the minor loops which are the hysteresis loops that only span portions of the input range, and (3) the initial ascending curve. As hysteresis is the major nonlinearity of PEAs and possesses detrimental effects on the positioning accuracy and stability margins of feedback control systems [95], compensation of hysteresis has always been a major concern in modelling and control of PEAs.

In [96], a PEA was modelled by means of the BoucWen model and a PID control was applied. The dynamic relationship governing the actuator is given by

$$
m \ddot{x}+c \dot{x}+k_{a} x=k_{b} k_{x} u+k_{b} k_{w} w,
$$

where $w$ is the evolutionary variable governed by (14); $m$ is the equivalent mass; $c$ is the damping coefficient; $k_{a}$ and $k_{b}$ are elastic constants; $x$ is the actuator displacement; $k_{x}$ and $k_{w}$ are constant gains; $n, \rho$, and $\sigma$ are the Bouc-Wen model parameters.

A Bouc-Wen based approach was introduced in [22] to compensate the hysteresis of piezoelectric actuators (see Figure 23) via a feedforward control. Indeed, feedback controllers for small systems, such as micro/nanoactuators, are strongly limited by the difficulty integrating the sensor. According to the multiplicative-inverse structure, the proposed compensator scheme was adapted to hysteresis with an advantage that no more computation was required for the compensator.

The hysteresis compensation is established using the following relationship:

$$
U=\frac{1}{d_{p}}\left(y_{r}+H(U)\right)
$$

$U$ being the applied electrical voltage; $d_{p}$ the piezoelectric coefficient; $y_{r}$ the target displacement of the actuator; $H(U)$ a nonlinear operator due to the Bouc-Wen model. Equation (26) is used as a compensator that employs $y_{r}$ as an input and $U$ as an output with respect to the scheme in Figure 24 .

To linearize the hysteresis behaviour of stack piezoelectric ceramic actuators, the feedforward linearization method, based on the Bouc-Wen model, and the hybrid linearization method, combining the feedforward method and PI feedback loop, were proposed and explored in [97]. The rapid control prototypes of the linearization controllers were established and tested, and the results showed that both the feedforward and hybrid linearization methods can linearize the hysteresis behaviour. Meanwhile, PEAs can exhibit an asymmetric hysteretic behaviour so that a modified Bouc-Wen model was proposed in [6] by introducing an input bias and an asymmetric factor into the standard Bouc-Wen hysteresis model.

\section{Conclusion}

This review reported the literature related to the utilization of the Bouc-Wen model for modelling hysterical behaviours of several vibration control systems. The review was organized into three sections that address specific issues: mathematical property of the Bouc-Wen model, identification of the model parameters, and applications of the Bouc-Wen model for 


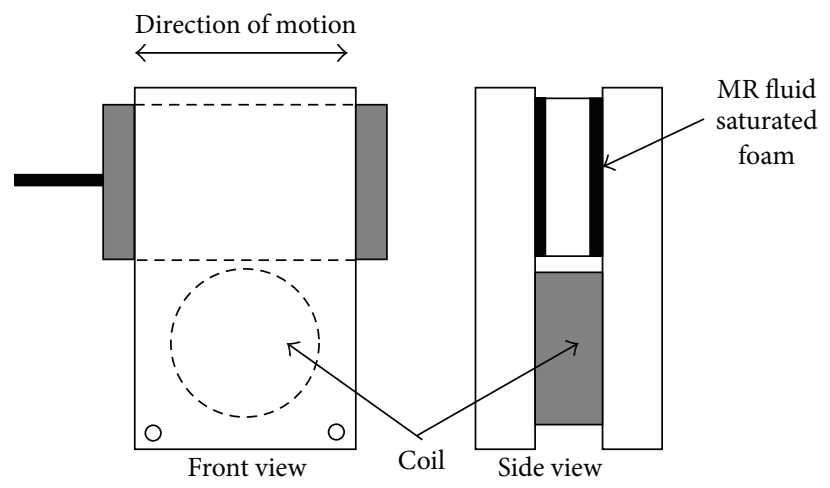

(a)

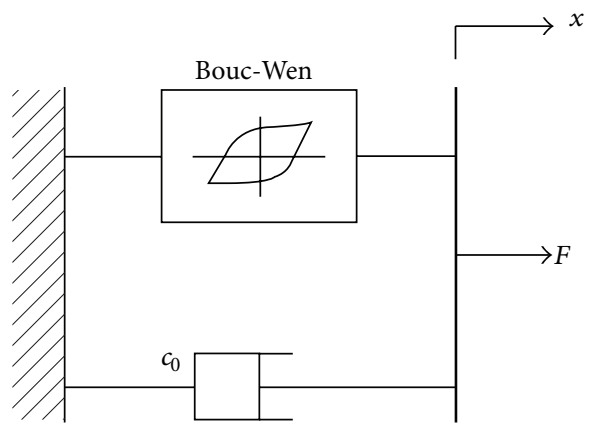

(b)

Figure 20: (a) Schematic diagram of shear mode MR damper; (b) mechanical model of the parallel plate MR damper $[15,18,19]$.

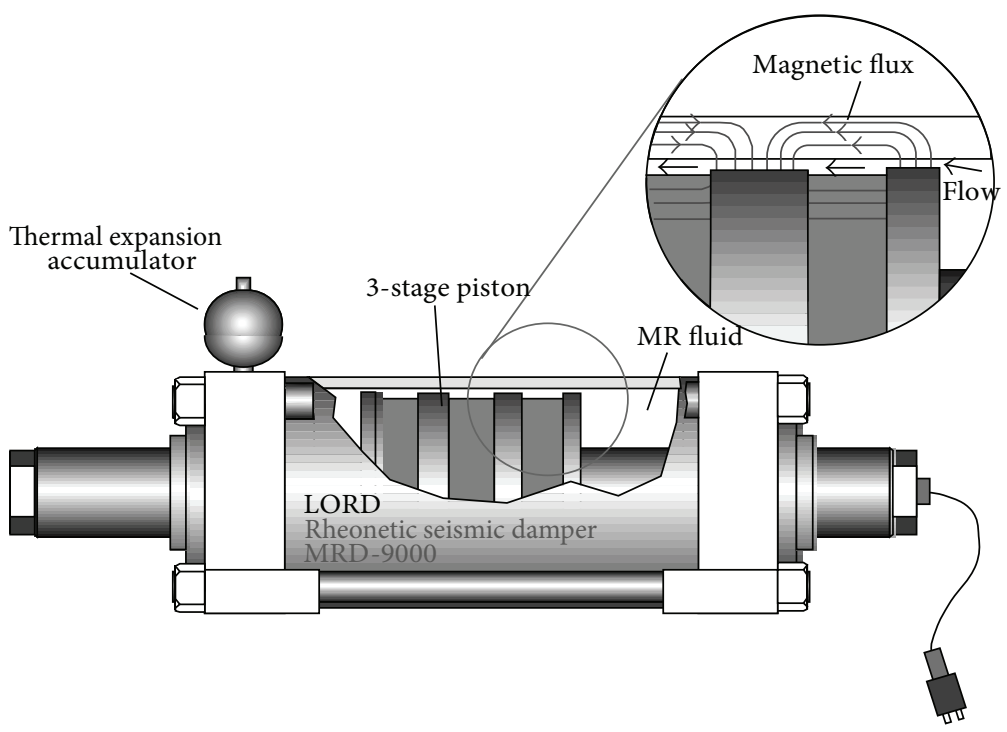

(a)

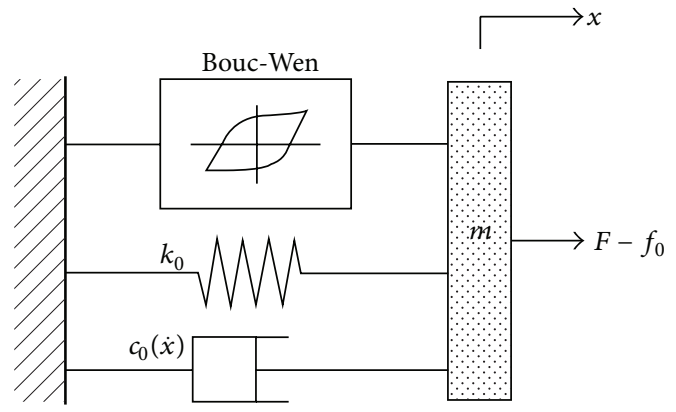

(b)

FIGURE 21: (a) Schematic of large-scale magnetorheological fluid damper; (b) Bouc-Wen model for large-scale MR dampers [15, 20].

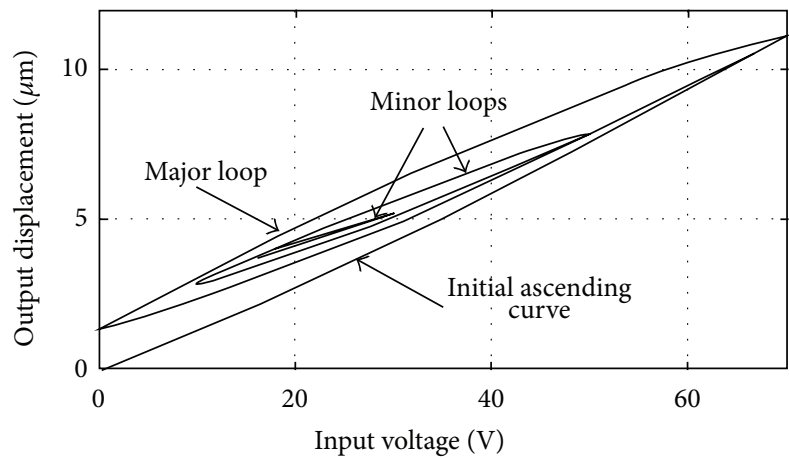

Figure 22: Hysteresis of a PEA [21].

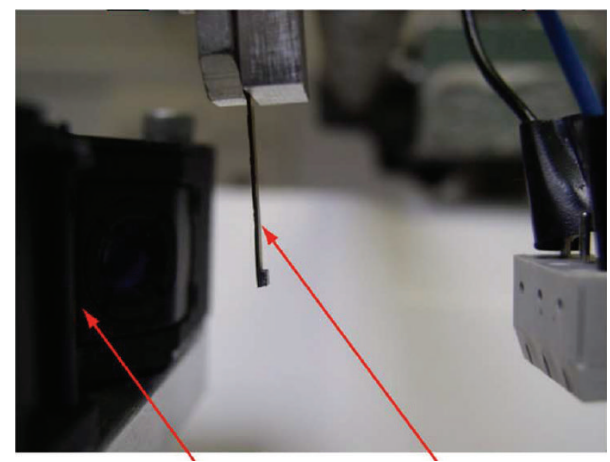

Displacement sensor Cantilevered piezoelectric actuator

Figure 23: Photography of the piezoelectric actuator [22].

the dynamical description of different types of vibration control systems. Section 2 described the theoretical basis of the Bouc-Wen model, its first formulation, and its successive modifications. Section 3 presented different approaches used for the identification of the Bouc-Wen model parameters. 


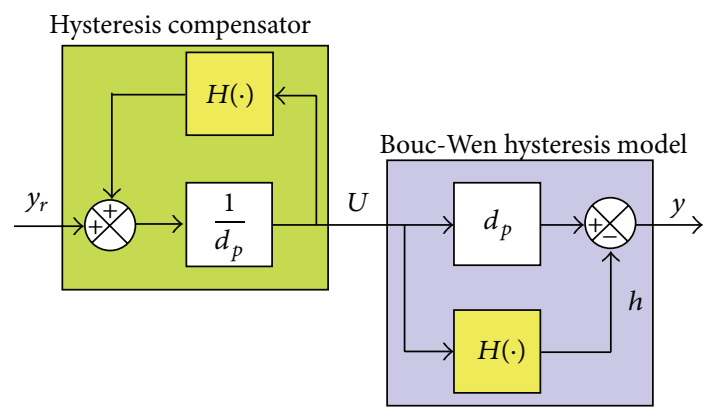

FIGURE 24: Bouc-Wen based compensator [22].

Section 4 provided several applications of the Bouc-Wen model for the modelling of devices extensively used in vibration control. Each section has presented what, from the authors' point of view, are the main contributions for the specific issue.

\section{Conflict of Interests}

The authors declare that there is no conflict of interests regarding the publication of this paper.

\section{References}

[1] M. Ismail, F. Ikhouane, and J. Rodellar, "The hysteresis BoucWen model, a survey," Archives of Computational Methods in Engineering, vol. 16, no. 2, pp. 161-188, 2009.

[2] R. Bouc, "Modèle mathématique d'hystérésis," Acustica, vol. 21, pp. 16-25, 1971.

[3] Y. K. Wen, "Method of random vibration of hysteretic systems," Journal of the Engineering Mechanics Division, vol. 102, no. 2, pp. 249-263, 1976.

[4] A. E. Charalampakis and V. K. Koumousis, "Identification of Bouc-Wen hysteretic systems by a hybrid evolutionary algorithm," Journal of Sound and Vibration, vol. 314, no. 3-5, pp. 571$585,2008$.

[5] S. K. Kunnath, J. B. Mander, and L. Fang, "Parameter identification for degrading and pinched hysteretic structural concrete systems," Engineering Structures, vol. 19, no. 3, pp. 224-232, 1997.

[6] H. Qin, N. Bu, W. Chen, and Z. Yin, "An asymmetric hysteresis model and parameter identification method for piezoelectric actuator," Mathematical Problems in Engineering, vol. 2014, Article ID 932974, 14 pages, 2014.

[7] S. Talatahari, M. Nouri, and F. Tadbiri, "Optimization of skeletal structures using artificial bee colony algorithm," International Journal of Optimization in Civil Engineering, vol. 2, no. 4, pp. 557-571, 2012.

[8] S. Pagano and S. Strano, "Wire rope springs for passive vibration control of a light steel structure," WSEAS Transactions on Applied and Theoretical Mechanics, vol. 8, no. 3, pp. 212-221, 2013.

[9] G. Di Massa, S. Pagano, E. Rocca, and S. Strano, "Sensitive equipments on WRS-BTU isolators," Meccanica, vol. 48, no. 7, pp. 1777-1790, 2013.

[10] H.-X. Wang, X.-S. Gong, F. Pan, and X.-J. Dang, "Experimental investigations on the dynamic behaviour of O-type wire-cable vibration isolators," Shock and Vibration, vol. 2015, Article ID 869325, 12 pages, 2015.

[11] X. Lu and Q. Zhou, "Dynamic analysis method of a combined energy dissipation system and its experimental verification," Earthquake Engineering \& Structural Dynamics, vol. 31, no. 6, pp. 1251-1265, 2002.

[12] S. Strano and M. Terzo, "A first order model based control of a hydraulic seismic isolator test rig," Engineering Letters, vol. 21, no. 2, pp. 52-60, 2013.

[13] M. Basili and M. De Angelis, "Optimal passive control of adjacent structures interconnected with nonlinear hysteretic devices," Journal of Sound and Vibration, vol. 301, no. 1-2, pp. 106-125, 2007.

[14] T. P. Gunston, J. Rebelle, and M. J. Griffin, "A comparison of two methods of simulating seat suspension dynamic performance," Journal of Sound and Vibration, vol. 278, no. 1-2, pp. 117-134, 2004.

[15] D. H. Wang and W. H. Liao, "Magnetorheological fluid dampers: a review of parametric modelling," Smart Materials and Structures, vol. 20, no. 2, Article ID 023001, 2011.

[16] S. J. Dyke, B. F. Spencer Jr., M. K. Sain, and J. D. Carlson, "An experimental study of MR dampers for seismic protection," Smart Materials and Structures, vol. 7, no. 5, pp. 693-703, 1998.

[17] B. F. Spencer Jr., S. J. Dyke, M. K. Sain, and J. D. Carlson, "Phenomenological model for magnetorheological dampers," Journal of Engineering Mechanics, vol. 123, no. 3, pp. 230-238, 1997.

[18] L. M. Jansen and S. J. Dyke, "Semiactive control strategies for MR dampers: comparative study," Journal of Engineering Mechanics, vol. 126, no. 8, pp. 795-803, 2000.

[19] F. Yi, S. J. Dyke, J. M. Caicedo, and J. D. Carlson, “Experimental verification of multi-input seismic control strategies for smart dampers," Journal of Engineering Mechanics, vol. 127, no. 11, pp. 1152-1164, 2001.

[20] G. Yang, B. F. Spencer Jr., H.-J. Jung, and J. D. Carlson, "Dynamic modeling of large-scale magnetorheological damper systems for civil engineering applications," Journal of Engineering Mechanics, vol. 130, no. 9, pp. 1107-1114, 2004.

[21] P. Jingyang and C. Xiongbiao, "A survey of modeling and control of piezoelectric actuators," Modern Mechanical Engineering, vol. 3, no. 1, pp. 1-20, 2013.

[22] M. Rakotondrabe, "Bouc-Wen modeling and inverse multiplicative structure to compensate hysteresis nonlinearity in piezoelectric actuators," IEEE Transactions on Automation Science and Engineering, vol. 8, no. 2, pp. 428-431, 2011.

[23] F. Ma, H. Zhang, A. Bockstedte, G. C. Foliente, and P. Paevere, "Parameter analysis of the differential model of hysteresis," Journal of Applied Mechanics, vol. 71, no. 3, pp. 342-349, 2004.

[24] M. C. Constantinou and M. A. Adnane, "Dynamics of soil-baseisolated structure systems: evaluation of two models for yielding systems," Report to NSAF, Department of Civil Engineering, Drexel University, Philadelphia, Pa, USA, 1987.

[25] N. M. Kwok, Q. P. Ha, M. T. Nguyen, J. Li, and B. Samali, "BoucWen model parameter identification for a MR fluid damper using computationally efficient GA," ISA Transactions, vol. 46, no. 2, pp. 167-179, 2007.

[26] T. T. Baber and Y. K. Wen, "Random vibration of hysteretic degrading systems," Journal of Engineering Mechanics, vol. 107, no. 6, pp. 1069-1087, 1981.

[27] T. T. Baber and M. N. Noori, "Random vibration of degrading pinching systems," Journal of Engineering Mechanics, vol. 111, no. 8, pp. 1010-1026, 1985. 
[28] T. T. Baber and M. N. Noori, "Modeling general hysteresis behavior and random vibration application," Journal of Vibration, Acoustics, Stress, and Reliability in Design, vol. 108, no. 4, pp. 411-420, 1986.

[29] F. Ikhouane and J. Rodellar, "On the hysteretic Bouc-Wen model. Part I: forced limit cycle characterization," Nonlinear Dynamics, vol. 42, no. 1, pp. 63-78, 2005.

[30] W. Zhu and X.-T. Rui, "Semiactive vibration control using a magnetorheological damper and a magnetorheological elastomer based on the bouc-wen model," Shock and Vibration, vol. 2014, Article ID 405421, 10 pages, 2014.

[31] A. G. Chassiakos, S. F. Masri, A. W. Smyth, and T. K. Caughey, "On-line identification of hysteretic systems," Journal of Applied Mechanics, vol. 65, no. 1, pp. 194-203, 1998.

[32] A. W. Smyth, S. F. Masri, A. G. Chassiakos, and T. K. Caughey, "Online parametric identification of MDOF nonlinear hysteretic systems," Journal of Engineering Mechanics, vol. 125, no. 2, pp. 133-142, 1999.

[33] J.-W. Lin, R. Betti, A. W. Smyth, and R. W. Longman, “On-line identification of non-linear hysteretic structural systems using a variable trace approach," Earthquake Engineering and Structural Dynamics, vol. 30, no. 9, pp. 1279-1303, 2001.

[34] C.-H. Loh, L. Y. Wu, and P. Y. Lin, "Displacement control of isolated structures with semi-active control devices," Journal of Structural Control, vol. 10, no. 2, pp. 77-100, 2003.

[35] J.-W. Lin and R. Betti, "On-line identification and damage detection in non-linear structural systems using a variable forgetting factor approach," Earthquake Engineering \& Structural Dynamics, vol. 33, no. 4, pp. 419-444, 2004.

[36] J.-L. Ha, Y.-S. Kung, R.-F. Fung, and S.-C. Hsien, "A comparison of fitness functions for the identification of a piezoelectric hysteretic actuator based on the real-coded genetic algorithm," Sensors and Actuators A: Physical, vol. 132, no. 2, pp. 643-650, 2006.

[37] R. L. Haupt and S. E. Haupt, Practical Genetic Algorithms, John Wiley \& Sons, New York, NY, USA, 1998.

[38] J. Kennedy and R. Eberhart, "Particle swarm optimization," in Proceedings of the IEEE International Conference on Neural Networks, pp. 1942-1948, December 1995.

[39] Y. Chae, J. M. Ricles, and R. Sause, "Modeling of a large-scale magneto-rheological damper for seismic hazard mitigation. Part I: passive mode," Earthquake Engineering and Structural Dynamics, vol. 42, no. 5, pp. 669-685, 2013.

[40] S. J. Li, H. Yu, and Y. Suzuki, "Identification of non-linear hysteretic systems with slip," Computers \& Structures, vol. 82, no. 2-3, pp. 157-165, 2004.

[41] Y. Q. Ni, J. M. Ko, and C. W. Wong, "Identification of nonlinear hysteretic isolators from periodic vibration tests," Journal of Sound and Vibration, vol. 217, no. 4, pp. 737-756, 1998.

[42] F. Ikhouane and O. Gomis-Bellmunt, "A limit cycle approach for the parametric identification of hysteretic systems," Systems \& Control Letters, vol. 57, no. 8, pp. 663-669, 2008.

[43] F. Ikhouane and J. Rodellar, "On the hysteretic Bouc-Wen model. Part II: robust parametric identification," Nonlinear Dynamics, vol. 42, no. 1, pp. 79-95, 2005.

[44] A. Rodríguez, N. Iwata, F. Ikhouane, and J. Rodellar, "Model identification of a large-scale magnetorheological fluid damper," Smart Materials and Structures, vol. 18, no. 1, Article ID 015010, 2009.

[45] S. Talatahari, H. Mohaggeg, K. Najafi, and A. Manafzadeh, "Solving parameter identification of nonlinear problems by artificial bee colony algorithm," Mathematical Problems in Engineering, vol. 2014, Article ID 479197, 6 pages, 2014.

[46] P.-Q. Xia, "An inverse model of MR damper using optimal neural network and system identification," Journal of Sound and Vibration, vol. 266, no. 5, pp. 1009-1023, 2003.

[47] D. H. Wang and W. H. Liao, "Modeling and control of magnetorheological fluid dampers using neural networks," Smart Materials and Structures, vol. 14, no. 1, pp. 111-126, 2005.

[48] S. F. Masri, J. P. Caffrey, T. K. Caughey, A. W. Smyth, and A. G. Chassiakos, "Identification of the state equation in complex non-linear systems," International Journal of NonLinear Mechanics, vol. 39, no. 7, pp. 1111-1127, 2004.

[49] Y. Yang and F. Ma, "Constrained Kalman filter for nonlinear structural identification," Journal of Vibration and Control, vol. 9, no. 12, pp. 1343-1357, 2003.

[50] H. Zhang, G. C. Foliente, Y. Yang, and F. Ma, "Parameter identification of inelastic structures under dynamic loads," Earthquake Engineering and Structural Dynamics, vol. 31, no. 5, pp. 1113-1130, 2002.

[51] E. N. Chatzi and A. W. Smyth, "The unscented Kalman filter and particle filter methods for nonlinear structural system identification with non-collocated heterogeneous sensing," Structural Control and Health Monitoring, vol. 16, no. 1, pp. 99-123, 2009.

[52] E. N. Chatzi, A. W. Smyth, and S. F. Masri, "Experimental application of on-line parametric identification for nonlinear hysteretic systems with model uncertainty," Structural Safety, vol. 32, no. 5, pp. 326-337, 2010.

[53] Z. Xie and J. Feng, "Real-time nonlinear structural system identification via iterated unscented Kalman filter," Mechanical Systems and Signal Processing, vol. 28, pp. 309-322, 2012.

[54] R. I. Skinner, W. H. Robinson, and G. H. McVerry, An Introduction to Seismic Isolation, Wiley, Chichester, UK, 1993.

[55] F. Naeim and J. M. Kelly, Design of Seismic Isolated Structures: From Theory to Practice, Wiley, Chichester, UK, 1999.

[56] H. Yoshioka, J. C. Ramallo, and B. F. Spencer Jr., "'Smart' base isolation strategies employing magnetorheological dampers," Journal of Engineering Mechanics, vol. 128, no. 5, pp. 540-551, 2002.

[57] C.-M. Chang and B. F. Spencer Jr., "Active base isolation of buildings subjected to seismic excitations," Earthquake Engineering and Structural Dynamics, vol. 39, no. 13, pp. 1493-1512, 2010.

[58] J. Fei, "Active vibration control of flexible steel cantilever beam using piezoelectric actuators," in Proceedings of the 37th Southeastern Symposium on System Theory (SST'05), pp. 35-39, IEEE, March 2004.

[59] J. M. Kelly, G. Leitmann, and A. G. Soldatos, "Robust control of base-isolated structures under earthquake excitation," Journal of Optimization Theory and Applications, vol. 53, no. 2, pp. 159180, 1987.

[60] S. Strano and M. Terzo, "A multi-purpose seismic test rig control via a sliding mode approach," Structural Control and Health Monitoring, vol. 21, no. 8, pp. 1193-1207, 2014.

[61] A. Calabrese, G. Serino, S. Strano, and M. Terzo, "Experimental investigation of a low-cost elastomeric anti-seismic device using recycled rubber," Meccanica, vol. 50, no. 9, pp. 2201-2218, 2015.

[62] J. C. Ramallo, E. A. Johnson, and B. F. Spencer Jr., "'Smart' base isolation systems," Journal of Engineering Mechanics, vol. 128, no. 10, pp. 1088-1099, 2002.

[63] I. Buckle, S. Nagarajaiah, and K. Ferrell, "Stability of elastomeric isolation bearings: experimental study," Journal of Structural Engineering, vol. 128, no. 1, pp. 3-11, 2002. 
[64] J. M. Kelly, "The role of damping in seismic isolation," Earthquake Engineering and Structural Dynamics, vol. 28, no. 3, pp. 3-20, 1999.

[65] S. Nagarajaiah and K. Ferrell, "Stability of elastomeric seismic isolation beargins," Journal of Structural Engineering, vol. 125, no. 9, pp. 946-954, 1999.

[66] B. F. Spencer Jr., E. A. Johnson, and J. C. Ramallo, "'Smart'isolation for seismic control," JSME International Journal, Series C: Mechanical Systems, Machine Elements and Manufacturing, vol. 43, no. 3, pp. 704-711, 2000.

[67] N. Makris, "Rigidity-plasticity-viscosity: can electrorheological dampers protect base-isolated structures from nearsource earthquakes," Earthquake Engineering \& Structural Dynamics, vol. 26, no. 5, pp. 571-591, 1997.

[68] S. Nagarajaiah, S. Sahasrabudhe, and R. Iyer, "Seismic response of sliding isolated bridges with MR dampers," in Proceedings of the American Control Conference, vol. 6, pp. 4437-4441, Chicago, Ill, USA, June 2000.

[69] D. Shook, P.-Y. Lin, T.-K. Lin, and P. N. Roschke, "A comparative study in the semi-active control of isolated structures," Smart Materials and Structures, vol. 16, no. 4, pp. 1433-1446, 2007.

[70] S. Sahasrabudhe, S. Nagarajaiah, and C. Hard, "Experimental study of sliding isolated buildings with smart dampers subjected to near-source ground motions," in Proceedings of the ASCE 14th Engineering Mechanics Conference (EM '00), Austin, Tex, USA, 2000.

[71] J. Zhang, L. He, E. Wang, and R. Gao, "A LQR controller design for active vibration control of flexible structures," in Proceedings of the Pacific-Asia Workshop on Computational Intelligence and Industrial Application (PACIIA '08), pp. 127-132, IEEE, Wuhan, China, December 2008.

[72] APC International, Piezoelectric Ceramics: Principles and Applications, APC International, 2011.

[73] G. F. Demetriades, M. C. Constantinou, and A. M. Reinhorn, "Study of wire rope systems for seismic protection of equipment in buildings," Engineering Structures, vol. 15, no. 5, pp. 321-334, 1993.

[74] M. Constantinou, A. Mokha, and A. Reinhorn, "Teflon bearings in base isolation II. Modeling," Journal of Structural Engineering, vol. 116, no. 2, pp. 455-474, 1990.

[75] M. Sasani and E. P. Popov, "Seismic energy dissipators for RC panels: analytical studies," Journal of Engineering Mechanics, vol. 127, no. 8, pp. 835-843, 2001.

[76] A. Lanzotti, M. Russo, R. Russo, F. Renno, and M. Terzo, "A physical prototype of an automotive magnetorheological differential," in Proceedings of the World Congress on Engineering (WCE 2013), vol. 3 of Lecture Notes in Engineering and Computer Science, pp. 2131-2135, 2013.

[77] A. Lanzotti, F. Renno, M. Russo, R. Russo, and M. Terzo, "Design and development of an automotive magnetorheological semi-active differential," Mechatronics, vol. 24, no. 5, pp. 426-435, 2014.

[78] K. Karakoc, E. J. Park, and A. Suleman, "Design considerations for an automotive magnetorheological brake," Mechatronics, vol. 18, no. 8, pp. 434-447, 2008.

[79] B. M. Kavlicoglu, N. C. Kavlicoglu, Y. Liu et al., "Response time and performance of a high-torque magneto-rheological fluid limited slip differential clutch," Smart Materials and Structures, vol. 16, no. 1, pp. 149-159, 2007.

[80] N. M. Wereley, J. U. Cho, Y. T. Choi, and S. B. Choi, "Magnetorheological dampers in shear mode," Smart Materials and Structures, vol. 17, no. 1, Article ID 015022, 2008.
[81] Z. Lou, R. D. Ervin, F. E. Filisko, and C. B. Winkler, "An electrorheologically controlled semi-active landing gear," SAE Technical Paper Series 931403, SAE International, 1993.

[82] Z. Lou, R. D. Ervin, and F. E. Filisko, "Preliminary parametric study of electrorheological dampers," Journal of Fluids Engineering, Transactions of the ASME, vol. 116, no. 3, pp. 570-576, 1994.

[83] N. M. Wereley and L. Pang, "Nondimensional analysis of semiactive electrorheological and magnetorheological dampers using approximate parallel plate models," Smart Materials and Structures, vol. 7, no. 5, pp. 732-743, 1998.

[84] Y.-T. Choi and N. M. Wereley, "Comparative analysis of the time response of electrorheological and magnetorheological dampers using nondimensional parameters," Journal of Intelligent Material Systems and Structures, vol. 13, no. 7-8, pp. 443451, 2002.

[85] N. M. Wereley, J. Lindler, N. Rosenfeld, and Y.-T. Choi, "Biviscous damping behavior in electrorheological shock absorbers," Smart Materials and Structures, vol. 13, no. 4, pp. 743-752, 2004.

[86] R. Stanway, J. L. Sproston, and N. G. Stevens, "Non-linear modelling of an electro-rheological vibration damper," Journal of Electrostatics, vol. 20, no. 2, pp. 167-184, 1987.

[87] E. W. Williams, S. G. Rigby, J. L. Sproston, and R. Stanway, "Electrorheological fluids applied to an automotive engine mount," Journal of Non-Newtonian Fluid Mechanics, vol. 47, pp. 221-238, 1993.

[88] N. D. Sims, R. Stanway, A. R. Johnson, and J. S. Yang, "Vibration isolation using a magnetorheological damper in the squeezeflow mode," in Smart Structures and Materials: Smart Structures and Integrated Systems, vol. 3668 of Proceedings of SPIE, pp. 520527, Newport Beach, Calif, USA, June 1999.

[89] Y. K. Ahn, J.-Y. Ha, Y.-H. Kim et al., "Dynamic characteristics of squeeze-type mount using magnetorheological fluid," Proceedings of the Institution of Mechanical Engineers Part K: Journal of Multi-body Dynamics, vol. 219, no. 1, pp. 27-34, 2005.

[90] A. Dominguez, R. Sedaghati, and I. Stiharu, "Modelling the hysteresis phenomenon of magnetorheological dampers," Smart Materials and Structures, vol. 13, no. 6, pp. 1351-1361, 2004.

[91] A. Dominguez, R. Sedaghati, and I. Stiharu, "A new dynamic hysteresis model for magnetorheological dampers," Smart Materials and Structures, vol. 15, no. 5, pp. 1179-1189, 2006.

[92] A. Dominguez, R. Sedaghati, and I. Stiharu, "Semi-active vibration control of adaptive structures using magnetorheological dampers," AIAA Journal, vol. 44, no. 7, pp. 1563-1571, 2006.

[93] A. Dominguez, R. Sedaghati, and I. Stiharu, "Modeling and application of MR dampers in semi-adaptive structures," Computers and Structures, vol. 86, no. 3-5, pp. 407-415, 2008.

[94] I. Mayergoyz and G. Bertotti, Eds., The Science of Hysteresis, vol. 3, Elsevier, St. Louis, Mo, USA, 2005.

[95] J. A. Main and E. Garcia, "Piezoelectric stack actuators and control system design: strategies and pitfalls," Journal of Guidance, Control, and Dynamics, vol. 20, no. 3, pp. 479-485, 1997.

[96] O. Gomis-Bellmunt, F. Ikhouane, and D. Montesinos-Miracle, "Control of Bouc-Wen hysteretic systems: application to a piezoelectric actuator," in Proceedings of the 13th International Power Electronics and Motion Control Conference (EPE-PEMC '08), pp. 1670-1675, Poznan, Poland, September 2008.

[97] D. H. Wang, W. Zhu, and Q. Yang, "Linearization of stack piezoelectric ceramic actuators based on Bouc-Wen Model," Journal of Intelligent Material Systems and Structures, vol. 22, no. 5, pp. 401-413, 2011. 


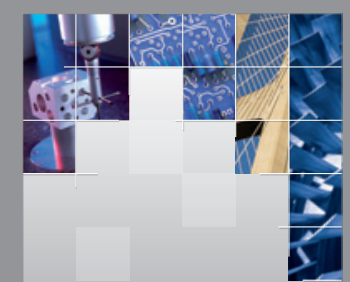

\section{Enfincering}
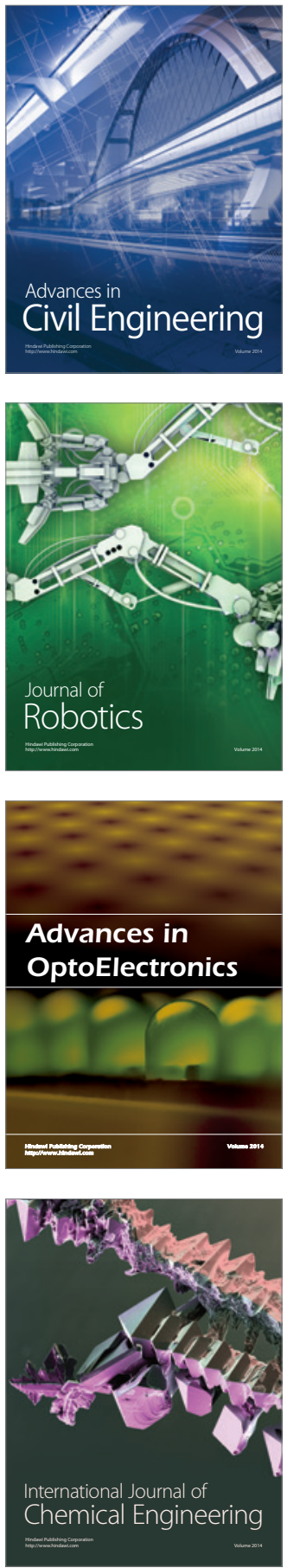

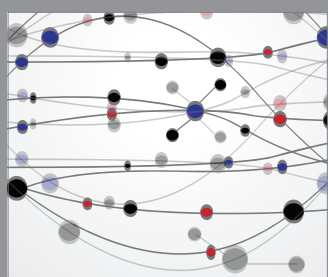

The Scientific World Journal

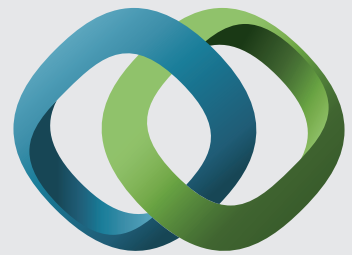

\section{Hindawi}

Submit your manuscripts at

http://www.hindawi.com
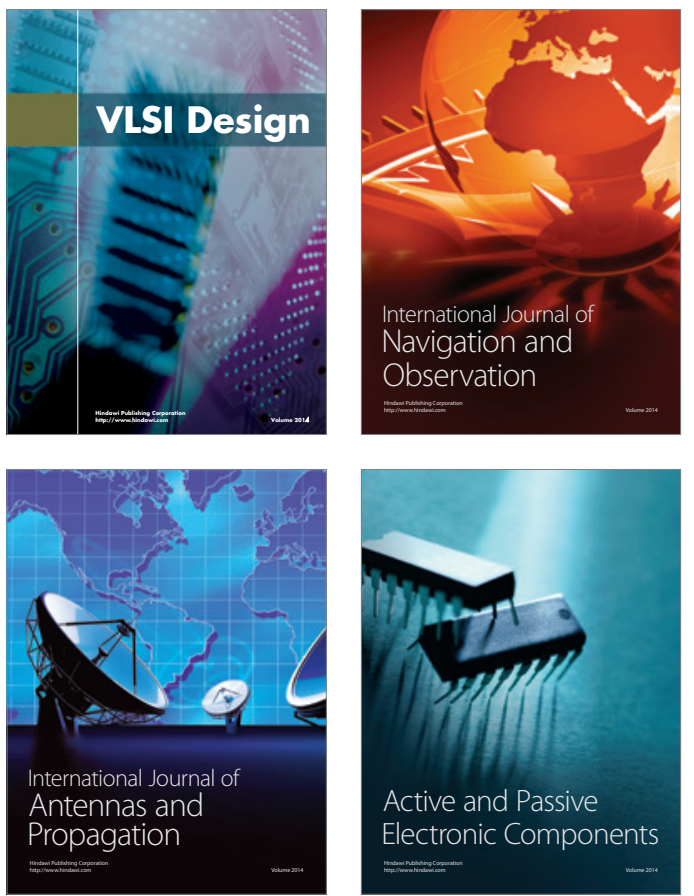
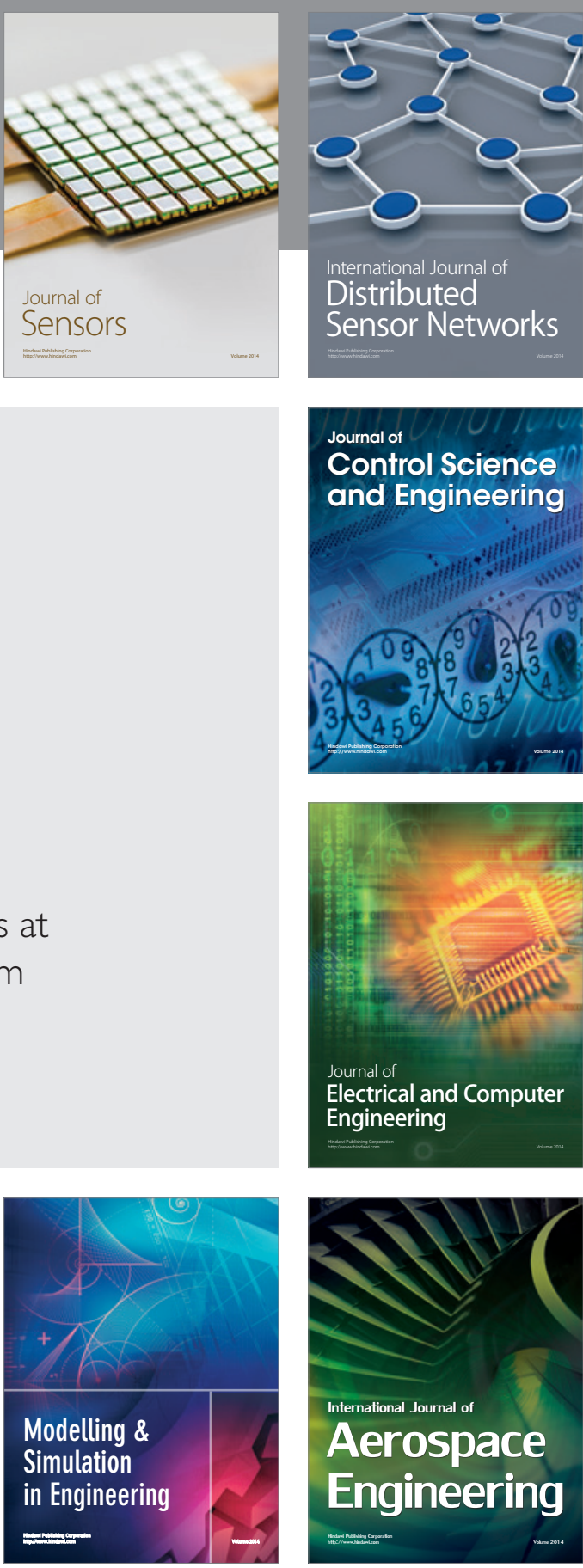

International Journal of

Distributed

Sensor Networks

Journal of

Control Science

and Engineering
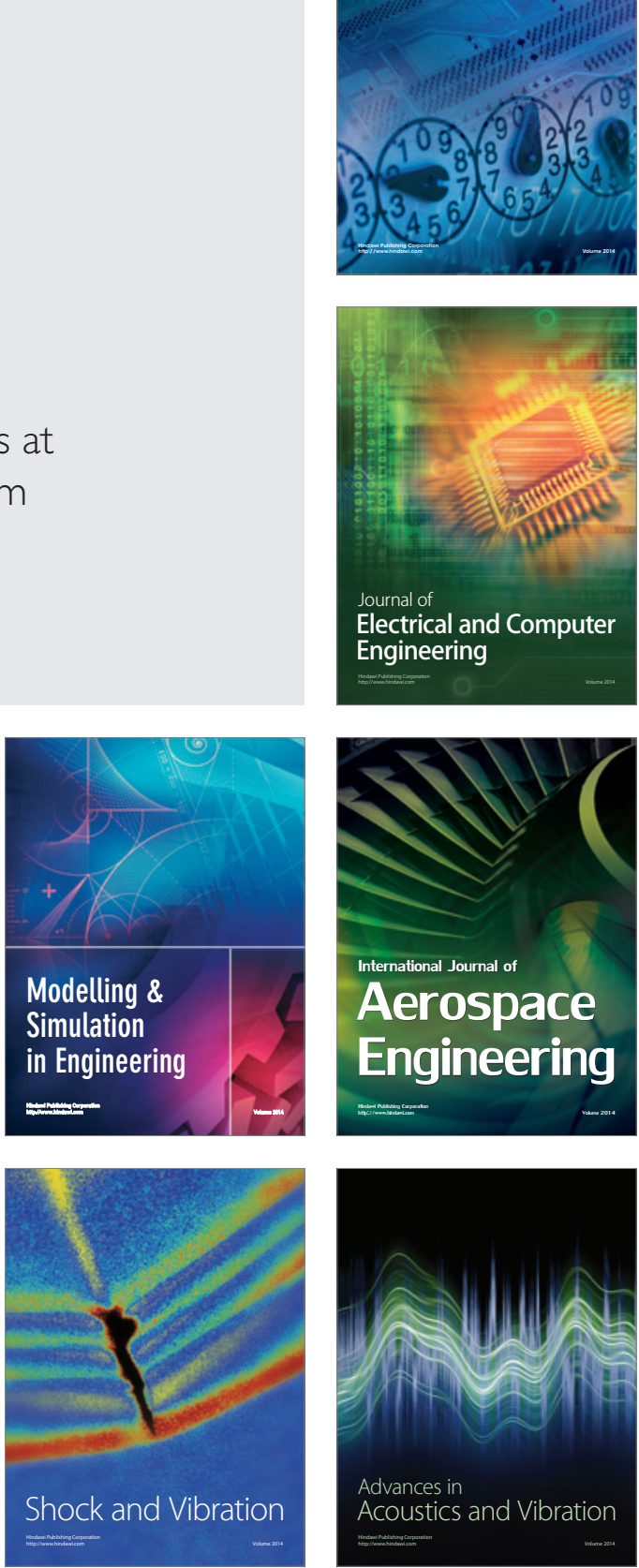